\section{Two brains but of a single mind}

\author{
John C. Marshall
}

The Duality of the Mind. By A.L. Wigan. Foreword by Joseph Bogen. Joseph Simon, PO Box 4071, Malibu, California 90265, USA: 1985. Pp.346. \$35.

THE question of how many angels can dance on the head of a pin has long since ceased to exercise our finest scholars. Yet if one wanted a contemporary analogue the following might suffice: how many minds may a man (or woman) manifest? "One", said René Descartes; "Two", said Arthur Wigan and Roger Sperry; "Fortytwo", said Franz-Joseph Gall.

The answer "Two" was sanctified by the award of the 1981 Nobel Prize in Medicine and Physiology to Sperry for the work that he and his colleagues had undertaken on commissurotomized patients. Some 20 years earlier, the eminent Los Angeles neurosurgeon Joseph Bogen had succeeded in reducing the incidence of major convulsive seizures in a small group of severely epileptic patients by sectioning the main cortical fibre tracts (commissures) that connect the two hemispheres of the brain. Sperry's intensive testing of the cognitive functions of these patients' now-disconnected cortices sparked a veritable explosion of interest in the differential psychological capacities of the left and right cerebral hemispheres. On one account of the results, Bogen's operation did not create two minds within a single body but rather revealed that we are all dual creatures, deluded in our belief that each of us is an indivisible self.

Bogen's (or Bogens') own interest in these issues has extended beyond the investigation and interpretation of his "splitbrain" patients to include the history of neurological speculation about cerebral duality. One fruit of his delving into the past is this splendidly handsome reprint of Arthur Wigan's Victorian epic of 1844, the scope and character of which is best shown by its full title: $A$ New View of Insanity: The Duality of the Mind Proved by the Structure, Functions, and Diseases of the Brain and by the Phenomena of Mental Derangement, and Shown to be Essential to Moral Responsibility. Indeed, Wigan's version of the "two-brain" theory is sufficiently close to some modern accounts for Bogen to name his own position "neowiganism".

Who might want to read the book today? To begin with, anyone who is concerned with the relationship between the neurosciences and society will be fascinated to see Wigan struggling to resolve the tension between biological determinism. educability and moral choice. Wigan's phraseology, and the certainty of his Victorian belief in scientific and ethical progress, may seem quaint to our more cynical ears:

The only limit to our researches on the nature of the mind, will ultimately be the boundary fixed by the Almighty to the powers of the human intellect - a point from which we are yet immeasurably distant. When we shall have cultivated all the faculties which $\mathrm{He}$ has bestowed upon us, to their full extent and perfection, then indeed will come the Millennium an issue towards which we are steadily and rapidly advancing. ... ;

yet his discussion of the potential conflicts between humanistic and scientific approaches to psychiatry and neurology is a good deal more honest and open than many current positions.

Second, the book should be read by all students of neuropsychology. Wigan is a pre-modern in that his work pre-dates the discovery of complementary hemispheric specialization that became (and remains) the central dogma of human neuro-

\section{A southern man}

\section{Derek Fordham}

Shackleton. By Roland Huntford. Hodder \& Stoughton/Atheneum: 1985. Pp.774. 19.95, \$29.95.

"Men wanted for hazardous journey. Small wages, bitter cold, long months of complete darkness, constant danger. Safe return doubtful. Honour and recognition in case of success." Thus Sir Ernest Shackleton chose to launch his 1915 Imperial Trans-Antarctic Expedition and was overwhelmed by thousands who wanted to join.

Years earlier, in 1900, Shackleton had been in the Antarctic for the first time and Roland Huntford spares no one in setting out the dreadful deficiencies and incompetence of that Discovery expedition under the leadership of Commander Robert Falcon Scott. During the expedition Shackleton came close to death and subsequently suffered the ignominy of being invalided home on Scott's orders. Scott's action was undeniably motivated by his dislike of Shackleton, who had shown himself to be a natural leader, in which respect Scott rightly doubted his own abilities.

In a spirit of defiant rivalry, heavily in debt and with a suspected weak heart. Shackleton set about organizing his own expedition, which sailed south in 1907. Shackleton and his team, poorly equipped and ill-prepared, penetrated to within 97 miles of the Pole before he decided to turn back, the hardest decision he ever had to make. but inescapable if he was to bring his team back alive. In so doing he laid psychology. Thus the notion that the left hemisphere is primarily implicated in language functions and the right in visuospatial functions is quite alien to Wigan's time. For Wigan, the hemispheres are full duplicates with respect to their intrinsic cognitive capacities; it is solely "slight inequalities" of "form, energy, and function" that suffice "to produce all the varieties of character which are to be found in the world". Accordingly, many of the case reports that Wigan describes are directed towards showing that "One cerebrum may be destroyed, yet the mind remain entire". The contemporary student would benefit greatly from the exercise of contemplating whether Wigan's conclusion derives merely from inadequate testing of non-verbal skills or rather contains an important truth that has been buried under our own obsession with complementary specialization.

John C. Marshall is in the Neuropsychology Unit, part of the Neuroscience Group at the Radcliffe Infirmary, Oxford $O X 26 \mathrm{HE}, U \mathrm{~K}$

bare the geography of the polar plateau and opened the route to the Pole for Scott and Amundsen to follow in 1911. His hero's return was marred by financial difficulties and the scandal of an errant brother, suspected of stealing the Irish crown jewels.

His resources in the face of failure were taxed again in October 1915 at the start of The Imperial Trans-Antarctic Expedition, when his ship, Endurance, having drifted helpless for 1,500 miles trapped in the pack-ice, was crushed and sunk in the Weddell Sea. For 600 miles Shackleton led his men over shifting, breaking ice to the floe edge and then across the stormswept open sea to the desolation of Elephant Island. Having established his men in a primitive camp he set off a few days later with five companions on a further 700 mile open boat journey across the Southern Ocean to South Georgia. A final desperate traverse of a range of unmapped icy mountains led to the whaling station from which the rescue of his expedition was mounted. Shackleton the survivor had once again brought his men back from the prospect of certain death.

But a world on the brink of war failed to recognize the staggering accomplishment of this impetuous man and he had to struggle to raise further funds for his last expedition, during which the misfortunes encountered on his earlier Antarctic forays took their toll. He died as his ship reached South Georgia, ironically the scene of his return from the dead in 1916.

This is Roland Huntford's second polar book - the first. published in 1979. having left the schoolboy image of Captain Robert Falcon Scott somewhat mangled and the subject of much controversy and deals with the very different but no 